\title{
Pocock e a historiografia como linguagem política
}

\section{Pedro Henrique Barbosa Montandon de Araújo}

Universidade Federal de Minas Gerais (UFMC)

\section{Pocock and the historiography as political language}

\section{Resumo}

O artigo que se segue tem a intenção de mostrar e discutir o programa historiográfico de John G. A. Pocock, a historiografia como linguagem política. Para tanto, seguiremos sua carreira, dos seus primeiros textos sobre contextualismo, passando pelos seus interesses nas teses linguísticas de Saussure e pelo paradigma de revolução científica de Kuhn, até seus últimos trabalhos sobre historiografia e comunidade política. É nossa intenção analisar esses textos não como uma evolução de seu pensamento, mas como diferentes estágios de um historiador e seu contexto, operando seus conceitos de acordo com os problemas que enfrenta e sendo influenciado pelos seus próprios trabalhos de diferentes maneiras e historicidades. Finalmente, acreditamos que, criando duas categorias, história e comunidade política, Pocock estabiliza seu programa historicista, defendendo a narrativa da comunidade política contra narrativas identitárias independentes.

Palavras-chave: John C. A. Pocock; Historiografia; Comunidade política; Linguagem política.

\section{Abstract}

The following essay has the intention to show and discuss the historiographic program of John G. A. Pocock, the historiography as a political language. To accomplish that, we will follow his career, from the first texts about contextualism, through his interest in Saussure's linguistic thesis and Kuhn's scientific revolution paradigm, until Pocock's later works about historiography and political society. It is our intention to analyze those texts not as an evolution of his thought, but as different stages of an historian and his context, operating his concepts according to the problems that he faces and being influenced by his own works in different ways and historicities. Finally, we believe that, creating two categories, history and political society, Pocock stabilize his historicist. program, defending the political society narrative against independent identity narratives.

Keywoords: John G. A. Pocock; Historiography; Political society; Political language. 

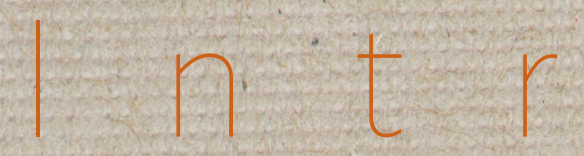

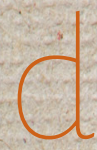
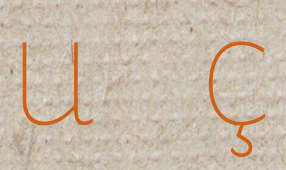

$\tilde{a}$

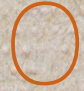

A - longo das últimas décadas, John G. A. Pocock gozou de um largo prestígio nas academias brasileiras de ciências sociais e de história. O recebimento favorável de sua obra se devia aos seus inovadores métodos para se estudar pensamento político, em que ideias transformavam-se em discursos historicamente proferidos. Nesse esteio, o historiador da escola de Cambridge recebeu uma ampla fortuna crítica, sendo alvo de resenhas, artigos e até mesmo de um livro inédito, organizado pelo professor do departamento de sociologia da Universidade de São Paulo, Sérgio Miceli, e que contém vários dos textos mais valorizados de Pocock.

No entanto, há um lado outro de Pocock menos explorado pelas universidades brasileiras, a saber, seus estudos sobre história da historiografia. Esta outra faceta, explicitada pelo próprio historiador no livro Political Thought and History, em 2009, nos parece ter um projeto tão ousado quanto o da linguagem política. Pocock estaria tentando conceber a própria historiografia como uma linguagem, transformando suas condições de efetivação em historicamente constituídos. Para compreender esse projeto, procuraremos retraçar os caminhos pelos quais Pocock se expressou historicamente.

\section{A trajetória historiográfica de John G. A. Pocock}

The Ancient Constitution and the Feudal Law (1987) foi o primeiro trabalho de grande fôlego de Pocock e também aquele em que introduziu suas preocupações com o contextualismo. Fruto de sua tese de doutoramento, escrita entre 1948 e 1952, essa obra apresenta o incipiente método do contextualismo linguístico e foi fortemente influenciada por Peter Laslett e Herbert Butterfield. Para se estudar pensamento político, defendia o autor, deveríamos estar atentos a dois pontos metodológicos basilares, o contex- 
to e a linguagem (POCOCK, 1987, p. $x-x i)$. O primeiro, em resposta direta à história das ideias tradicional, se referia à necessidade de, ao estudar um escrito político, entendê-lo, analisá- lo e referenciá-lo ao contexto de sua própria época, às discussões em voga quando o documento foi escrito e não mobilizá-lo como pertencente a um mundo quintessencial dos gênios, que discutiam temas mais altos, sem preocuparem-se com as vicissitudes do próprio tempo. O segundo, como escolha de desenvolvimento do primeiro, seria tratar aquele pensamento, aquela ideia, como discurso, proferimento e, portanto, ato. Se o pensador e seus escritos estão concatenados à sua própria época, também deveriam estar suas ideias presas à esfera sublunar. Ao responder às inquietudes do próprio tempo e espaço, as ideias se tornavam atos em vista de modificar o próprio mundo. Portanto, o direito consuetudinário não nasceria como antecipação ou fundamentação de um pensamento conservador burkeano, mas sim como resposta às crises inglesas do século XVII.

Na história do pensamento político clássica, o pesquisador ligaria a ideia à tradição do pensamento. Pocock, por outro lado, começa a vislumbrar uma outra metodologia: conectar a experiência e as ideias do autor à sua própria época (POCOCK, 1964, p. 190). Mas esse pensamento, que nasce em relação ao próprio tempo do enunciador, não seria reflexo das estruturas socioeconômicas e sim somente uma forma do próprio autor se situar em seu tempo, de interrogá-lo, de encontrar soluções para os dilemas que ele e seus contemporâneos vivem (POCOCK, 1964, p. 199). Neste momento, Pocock opera uma outra mudança importante, rompendo com uma tradição marxista de considerar ideias como epifenômenos de estruturas materiais. As ideias teriam uma temporalidade própria, uma história própria, que seria influenciada pelo tempo de sua expressão, mas que não seria consequência das estruturas que a cercam (POCOCK, 1971, p. 12).

Mas se uma ideia é sempre direcionada ao seu contexto de proferimento, ou seja, é situacional, a história do pensamento político não se tornaria um estudo de átomos isolados e sem diacronia, sem passagem do tempo? É enfrentando tal dilema que Pocock refinará seu método, nos apresentando, já na década de 1960, um apro- 
fundamento do seu entendimento de linguagem política. Apesar de ser direcionada ao próprio tempo, uma ideia não seria um simples relato de experiência sensorial, como se, ao se defrontar com o próprio tempo, surgisse um insight originalíssimo desse ser e seu entorno. Ao sermos inseridos no mundo, não seríamos inseridos somente num mundo materialmente existente, mas também abstratamente existente, um mundo que já teria construído seus saberes, opiniões e crenças, que já teria construído suas próprias linguagens. Portanto,

A linguagem que um autor emprega já está em uso. Foi utilizada e está sendo utilizada para enunciar intenções outras que não as suas. Sob esse aspecto, um autor é tanto um expropriador, tomando a linguagem de outros e usando-a para seus próprios fins, quanto um inovador que atua sobre a linguagem de maneira a induzir momentâneas ou duradouras mudanças na forma como ela é usada (POCOCK, 2013a, p. 29).

Ao sermos iniciados nesse mundo, seríamos iniciados não só às coisas, mas também às abstrações. Essas abstrações se agrupam, formando modelos de se compreender e de se expressar o mundo que está em nós e ao nosso redor. Elas perpassam os dilemas dos acontecimentos no tempo, nos fornecendo chaves de leitura para esses, momentos e também sendo modificadas pelas idiossincrasias de cada evento. Ao se ajuntarem, essas abstrações reunem pessoas a partir de vocabulários comuns, de conceitos compartilhados. Dessa forma, uma linguagem agrupa e expressa os anseios de grupos políticos, se tornando uma linguagem política.

Ela [a linguagem] alude a elementos de uma experiência da qual ela provém e com os quais ela torna possível lidar, e de uma linguagem corrente no discurso público de uma sociedade institucional e política, pode-se esperar que ela aluda a instituições, autoridades, valores simbólicos e acontecimentos registrados que ela apresenta como parte da política dessa sociedade e dos quais deriva muito do seu próprio caráter (POCOCK, 2013a, p. 36).

É sob esśa perspectiva, de linguagens políticas, que Pocock conceberá seu Machiavellian Moment (2003), publicado em 1975. Influenciado por Hans Baron e Bernard Bailyn, Pocock identificou a formação do republicanismo moderno no quattrocento e cinquecento italiano como um processo de retomada das ideias aristotélicas, princi- 
palmente no que se referia à cidadania ativa (POCOCK, 2013b, p. 273). A retomada do republicanismo viria pela retomada de uma linguagem republicana pelos humanistas cívicos. Ao invés de trabalhar com ideias de longa duração ou até mesmo pretensamente atemporais, Pocock desloca-se para os discursos, ensejados por uma linguagem que os compõem com conceitos e que, esta sim, teria uma longa duração.

Essa linguagem, originada na politeia grega, teria percorrido tempos e espaços diferentes, modificando-se ao mesmo tempo em que transformava as ações e instituições dos homens. Essa trilha diacrônica se casa com a análise do momento, em que homens, influenciados por linguagens historicamente constituídas, projetam-se para resolver os problemas do próprio tempo, formulando seus discursos como atos, em vista de modificar o panorama que os é apresentado. Dessa maneira, Pocock delimitou de outra maneira o período moderno (early modern), concebendo-o como um mundo que já não é medievo mas também não é industrial (POCOCK, 2013b, p.21) e que fez com que Joyce Appleby (1992, p.323) classificasse a Revolução Americana como a última grande realização do Renascimento. Ao publicar seu Machiavellian Moment, Pocockatingiu um nível de reconhecimento que agregou entusiastas como Quentin Skinner e Nicholas Phillipson (1993) - que editaram um livro sobre os discursos políticos no período moderno britânico, com um posfácio listando as obras publicadas de Pocock-e Markku Peltonen (2004), que utilizando da mesma metodologia e partindo da tese de um humanismo temporalmente expandido, contestou Pocock, afirmando que a linguagem republicana havia aportado em solo inglês um século antes, nas figuras de Thomas Starkey e Thomas Morus.

Contemporaneamente, Pocock inicia um processo de sistematização da sua teoria, delimitando as concordâncias e discordâncias de seus colegas mais próximos, como-Skinner e Laslett. Essa sistematização, que nos parece mais aberta à experimentação do que um arranjo cirurgicamente circunscrito, é publicizada em seu livro Politics, Language and Time, de 1971 e se extende, com algumas modificações, até pelo menos o seu Virtue, Commerce and History, de 1985. 
Começando pelos elementos que não sofreram mudanças, Pocock aprofunda seu entendimento de linguagem política ao se aproximar de Ferdinand de Saussure. O par explicativo autor/ contexto ganha um novo vocabulário, incorporando conceitos como parole, langue e lance. Sendo a langue o encontro sincrônico de várias linguagens, que compõem a tessitura linguística, o contexto linguístico de uma sociedade, a parole seriam as performances que os indivíduos, inseridos nessa tessitura linguística de várias linguagens, efetuam no mundo, com uma marca própria de leitura do seu entorno, e - lance a modificação de linguagens e tessituras a partir de uma inovação linguística efetuada pelo indivíduo e sua performance, legando à sociedade e à posteridade uma nova linguagem.

É esse Pocock, dos discursos políticos formando tessituras linguísticas, da relação langue-parole e do encontro da virada linguística com o historicismo, que parece estar presente nos escritos de Marcelo Jasmin (2005) e João Feres Júnior (MARTINS \& FERES JÚNIOR, 2006) e que, apesar das mudanças a que naturalmente uma proposta historiográfica pode se submeter ao longo do tempo, é o núcleo do pensamento de Pocock.

Também dessa fase saussureana advêm outras interpretações de Pocock, dentre elas a de um estruturalismo linguístico paradigmático. Nos referimos à leitura de David Boucher (1985a), John Geerken (1979), Diego Ambrosini (2013), Eunice Ostrensky e Patricio Tierno (2013), segundo os quais as linguagens políticas conformariam um contexto que estruturaria o pensamento dos enunciadores, para que eles, então, se reportassem de volta a esse contexto, modificando-o. Segundo Ostrensky e Tierno (2013, p. 16 7), "as linguagens funcionariam quase à maneira de paradigmas 'na estruturação do pensamento e da fala'". Para Ambrosini (2013; p. 266-267), o enfoque de Pocock na linguagem, em contraponto ao enfoque inténcionalista de Skinner, faria com que o historiador neozelandês desse ênfase à estrutura ao invés da agência. Já Ceerken (1979) acusa o Machiavellian Moment de não ser um trabalho histórico, mas sim um estudo estruturalista atemporal.

Ainda em 1981, Pocock irá desacreditar a visão estruturalista de seu 
programa historiográfico, ao mesmo tempo em que se defendia de outros ataques. O seu método, diz, é baseado na afirmação de que linguagens sobrevivem ao tempo de seus criadores e usuários, reaparecendo em outras épocas e sendo sempre modificadas por aqueles que reagem a elas, especialmente em sociedades que empregam complexas tradições literárias. As linguagens, apesar de constituirem uma estrutura paradigmática, permeariam o mundo de forma fluida, sem determinar esferas de pensamento ou grandes mentalidades. Uma concepção que não seria, para Pocock (1981, p. 52-53), uma abordagem estruturalista ou idealista.

A linguagem para Pocock, mesmo quando se utiliza de Saussure, não é uma esfera a qual os homens se reportam: as linguagens são múltiplas em suas características, histórias e geografias. Assim, se elaboram não por diferenças de essência, mas sim por serem constituídas pelos próprios discursos proferidos por personagens em situações específicas. Elas também não possuem a pureza de uma ideia-unidade, que resiste às intempéries do tempo, mas são sim mescladas com outras linguagens, que fazem com que um autor, ao proferir seu discurso, utilize elementos de várias delas. As linguagens, portanto, se interpenetram, sendo difícil estabelecer a territorialidade de cada uma delas. Essa decomposição entre indivíduo e linguagem, decorrente de uma separação de indivíduo e contexto, não nos parece estar presente em Pocock ou Skinner. A linguagem, ou o contexto, só existe em sua efetuação, em sua pragmática, constituída por atos humanos

Ao mesmo tempo, a perspicaz acusação de certo estruturalismo tem seus motivos. Em seu Politics, Language and History, de 1,971, Pocock se mostra fascinado com A Estrutura das Revoluções Científicas, de Thomas Kuhn, e, mesmo sabendo da relutância de Kuhn de aplicar śua tese às ciências humanas, toma de empréstimo várias de suas ideias. Para Pocock, esse trabalho de história da ciência fez com que leito-

1 Não por acaso, Pocock, e principalmente Skinner, baseiam seu contextualismo linguístico nos jogos de linguagem de Wittgenstein e nos atos de fala de John Austin. Ao mesmo tempo, admitimos que durante sua aproximação à teoria de paradigmas científicos de Thomas Kuhn, Pocock parece conceber linguagens como estruturas. Porém, como este artigo irá demonstrar, o historiador neozelandês abandonará essa premissa. 
res pensassem a história da ciência como essencialmente uma história do discurso e da linguagem. A ciência seria configurada, então, por paràdigmas que definem não só as respostas, mas também as perguntas e problemas a serem investigados. Esses paradigmas seriam protegidos por uma comunidade científica que aprovaria e desaprovaria as pesquisas de acordo com o paradigma em voga. Ocorreria uma revolução científica quando o paradigma cessasse de responder satisfatoriamente aos problemas e estímulos de uma determinada época. A partir desse momento haveria uma reordenação e redefinição das disciplinas, linguagem, perguntas e respostas, constituindo um novo paradigma que funcionasse satisfatoriamente e que redistribuísse a autoridade científica para outras pessoas, formando uma nova comunidade científica (POCOCK, 197.1, p. 13).

Assumindo a impossibilidade de se transpor a ideia de comunidade científica para a comunidade política, Pocock utilizará mais da ideia de paradigma e linguagem para o estudo do pensamento político. A linguagem política, apesar de ser retórica e não científica, moldaria a forma de seus usuários lidarem com a política, controlando não só as respostas corretas aos problemas encontrados, mas ditando, também, quais são os problemas a serem desafiados e resolvidos. Dessa forma, Pocock pretendia religar a conexão entre as instituições políticas e o pensamento político. Um interessante exemplo que Pocock usa, e que depõe a favor de uma leitura estruturalista de seu programa historiográfico, seria a mudança de um paradigma pré-moderno de fluidez da história, que veria os tempos vindouros como dependentes da interferência sagrada, divina ou heroica, para um paradigma do ato revolucionário, que veria o futuro como secularmente aberto e elaborado pelas ações dos homens (POCOCK, 1971, p. 273).

Acusando Pocock de ter uma contraditória teoria relativista e objetivista, Boucher (1985b) afirma que, se a visão paradigmática advém de Kuhn, é porque ela está enraizada no idealismo britânico de Collingwood e Oakeshott. E, continuando a crítica, assevera que transformar a linguagem política em paradigma, é transformar a própria fala em ato político. A linguagem se tornaria lugar de disputa, onde os mais 
habilidosos deteriam o paradigma societário (BOUCHER, 1985a, p. 165).

Mas essas fases, a paradigmática e a saussureana, conviveram em períodos idênticos ou, apesar da tangência, tiveram predominância em tempos diferentes? Acreditamos que a segunda hipótese seja mais verossímil. A fase paradigmática está sistematizada, por inteiro, no seu livro Politics, Language and Time, de 1971, e rapidamente já é modificada no artigo The State of Art, de 1985, quando propõe ver cada linguagem como portadora do próprio paradigma. Nas palavras do autor,

Cada uma dessas linguagens, sejam quais forem suas origens, exercerá o tipo de força que tem sido chamada de paradigmática [...]. Ou seja, cada uma delas contribuirá com informações selecionadas como relevantes ao exercício e à natureza da política, e favorecerá a definição de problemas e valores políticos de uma determinada forma, e não de outra (POCOCK, 2013a, p. 32).

Mesmo se mostrando reticente à incorporação que tinha feito do conceito de paradigma de Thomas Kuhn, Pocock não abandona a ideia, mas tenta reformulá-la, imbuindo-a de pluralidade. Somente em 2009 esse programa historiográfico é desacreditado pelo próprio Pocock (2009, p. xii), afirmando que, apesar de haver alguns momentos da história da linguagem política que possam parecer paradigmáticos, a natureza das comunidades científicas era diferente das comunidades políticas. Circunscrita nesses anos, a proposta aparecerá com certa força no Machiavellian Moment e de forma mais tímida no Virtue, Commerce and History. Quanto mais distante temporalmente do epicentro de 1971 . mais frouxa é a adesão de Pocock à proposta.

Já a fase saussureana não parece seguir a ascensão, o declínio e a queda da fase paradigmática. Em Politics, Language and Time, por exemplo, não há uma única citação ou aproximação a Saussure, sendo uma obra preocupada com uma visão paradigmática das comunidades políticas. Também não há referência à linguista em seu artigo de 1981 The Reconstruction of Discourse, que faz um interessante retorno às ideias de atos de fala, com as quais Skinner estava trabalhando. 0 aparecimento vigoroso de Saussure nos textos de Pocock acontecerá somente com a introdução do livro Virtue, Commerce and History, chamada de The State of Art. Esse texto se preocu- 
pará em discutir o Estado da Arte da própria metodologia, reformulando-a com novas bases, explicitando o papel da langue, da parole e do lance nà sua história dos discursos políticos. A afiliação a Saussure continuará forte em seu artigo The Concept of a Language and the Métier d'historien, de 1987.

\section{Pocock e a história da historiografia}

Mas, se há essa faceta amplamente discutida de Pocock, há também uma outra preocupação historiográfica que o instiga e que geralmente passa desapercebida, que é a sua análise sobre história da historiografia. Apesar do seu primeiro texto sobre o assunto ser antigo, somente mais recentemente é que o historiador em questão lançou títulos de peso sobre o assunto, do Discovery of Islands à coleção Barbarism and Religion, quando ele parece interessado em dialogar sua história da historiografia com o contextualismo linguístico.

Destacamos, desses seus primeiros textos de meados do século $X X$, a in- tenção de se delimitar as fronteiras entre a história da historiografia e a filosofia da história. Sucintamente, em, sua resenha $A$ Branch of the Subject, Pocock (1958) critica os historiadores que fazem da história da historiografia um rol de inovações filosóficas, defendendo que tal pesquisa deveria investigar como os homens percebiam o passado e de quais formas essa percepção influenciava suas relações sociais. Alguns anos adiante, ele sistematiza a diferença dos campos, dizendo ser função da filosofia da história investigar os postulados metodológicos e teóricos da disciplina, elucidando a lógica com que os historiadores lidam com a pesquisa. Por sua vez, a história da historiografia deveria entender a história como, atividade social de um certo grupo que tem linguagem e conceitos que definem os problemas a serem investigados e o modo de se construir suas respostas (POCOCK, 1962). A proposta de história da historiografia de Pocock nos parece sugerir uma examinação para além da simples análise da disciplina no tempo, buscando compreender também a relação da percepção do passado de uma sociedade com a historiografia 
que produz, mesclando as categorias de sujeito-objeto².

Como exemplo, o autor diz que não é possível compreender a revolução historicista dos séculos XVIII e XIX pelos próprios termos, sendo necessário investigar as mudanças na sociedade, bem como nas abstrações filosóficas da época, para se compreender essa nova forma de percepção de história (POCOCK, 2009, p. 146). Ademais, uma historiografia teria suas condições de existência: apesar de ser escrita por um indivíduo, este deve se perceber em uma comunidade que existe para além da finitude de uma vida humana, criando a noção de que o próprio indivíduo é parte de uma história que pode ser maior do que a dele; ela é composta por narrativas que, mesmo na intenção de serem totalizantes, dizem respeito a uma forma, historicamente delimitada, de compreender o passado, e é constituída por uma pluralidade de perspectivas históricas que entram em embate. Finalmente, a historiografia seria dotada, necessariamente, de um caráter diacrônico,

2 Essa sua fase inicial, inclusive, é aquela na qual ele se mostra excessivamente interessado na definição das áreas, diferenciando história do pensamento político de história da filosofia política e de teoria política, por exemplo (POCOCK, 1964). pois seria ela a intercessão entre as relações do presente de quem a escreve, com suas percepções do passado, e o, próprio passado, que como tradição sustenta o presente em seus valores, crenças e atividades, indispensável para a noção de continuidade entre passado e presente.

Essas definições claras de objeto nos apontam para uma obsessão teórica de Pocock nas décadas de 1950 e 1960, de encontrar regularidades de teorias, atividades ou princípios em culturas radicalmente diferentes. Não por acaso, em 1968, o historiador em questão afirmaria que toda sociedade possui uma filosofia da história (POCOCK, 2009, p. 187). Por detrás dessa ambição, haveria um problema genuíno: fundamentar as bases do estudo para que sua proposta não ficasse refém do próprio historicismo proposto. Afinal, se todo conhecimento é fruto das relações históricas de percepção do mundo, o que faria do nosso esforço de se entender o passado algo válido, já que seriam simples e efêmeras percepções de outros tempos? Essa barreira ao historicismo desenfreado fará com que Boucher (1985b, p. 775) 
acuse Pocock de contraditório, pois não aplicava as propostas historiográficas nas próprias pesquisas.

De frente para o abismo historicista, Pocock toma o caminho de Thomas Kuhn, iniciando sua fase paradigmática já citada. É ainda interessante notar que, em seu Political Thought and History, obra na qual o autor pretende fazer uma retrospectiva de seus escritos, haja uma abrupta interrupção na parte de história da historiografia, entre um texto escrito em 1968 e outro em 1996.

Saltando algumas décadas, encontramos o nosso personagem bradando em um linguajar um pouco diferente. Logo na primeira página de sua longa coleção Barbarism and Religion, Pocock afirmaria que a obra Declínio e Queda, de Edward Gibbon, ainda é vista como uma obra de diálogo historiográfico e não como um testemunho do século XVIII britânico. Seu intento na coleção seria justamente o de entender Declínio e Queda nos termos da própria época (POCOCK, 2004, p. 1). Poderíamos ver tal declaração somente como uma rusga acadêmica, mas, por esse caminho, perderíamos uma nova fase de
Pocock, que tentará incluir a historiografia em seu contextualismo linguístico.

Declínio e Queda seria, apesar da investigação sobre a história romana, um produto do lluminismo, que formataria a visão historiográfica de Cibbon sob uma linguagem da própria época (POCOCK, 2013b, p. 187). A clara visão etapista em que a obra é estruturada, por exemplo, seria proveniente do lluminismo escocês, em especial de lorde Kames. Mas não só a metodologia utilizada é produto do contexto histórico, mas também o são as teses, que a partir da perspectiva de um presente, sobre um passado, interpreta esse com as linguagens daquele.

Uma das teses de Gibbon seria, por exemplo, de que a república romana teria se corrompido devido a seu sucesso, assim como todas as repúblicas que, ao nascerem virtuosas, se expandem com facilidade e, ao se expandirem, abrem oportunidade para comandantes militares e especuladores econômicos imporem sua ambição e avareza, germinando a corrupção e declínio da república (POCOCK, 2013a, p. 190). Ao mesmo tempo, 
complementa Gibbon, essas virtudes não teriam ressurgido com uma suposta virtude agrária bárbara, já que, para ele, a virtude é sempre cívica'(POCOCK, 2013a, p. 197). Em suma, Gibbon estaria dialogando tanto com a tese clássica de um ciclo de geração e corrupção da república, quanto com a discussão sobre a geração agrária e cívica de uma república, tema que reverberava a preocupação dos homens do século XVII, preocupados com os rumos de uma sociedade que mercantilizava as relações comunitárias.

A permanência do método do contextualismo linguístico, em especial na década de 1980, fica explícito. Ao estudarmos um texto, deveríamos analisar as influências do contexto sobre ele. Mas isto basta? Basta dizer que o lluminismo escocês e a linguagem da virtude cívica influenciaram o trabaIho de Gibbon? Bastaria se os conceitos com que analisamos o contexto fossem perenes e inequívocos. Torna-se necessário, então, ao historiador da historiografia o esclarecimento dos conceitos históricos utilizados nas obras historiográficas.

Sob esse intuito, Pocock discutirá em seu primeiro volume de Barbarism and Religion, o que ele entende por lluminismo, entrando em desacordo com, o renomado Franco Venturi (2003). Se para esse historiador italiano o lluminismo seria um movimento de homens de letras que se consideravam pensadores seculares e que se colocavam como guias para o progresso e reforma da sociedade, excluindo a Inglaterra e Edmund Burke do movimento, para Pocock o lluminismo seria múltiplo, marcado por movimentos em disputa e caracterizado pela emergência de "sistemas de Estados" comuns em sociedades civis e comerciais, que abriam a possibilidade de se desafiar as guerras de religião, sem caírem na ideia de uma monarquia que centralizava o corpus moral, e que demandavam a separação da Igreja do Estado, bem como a impossibilidade da soberania eclesiástica subjugar a soberania estatal. Se o lluminismo de Venturi tinha como premissa a razão dos philosophes, o de Pocock se fundamentava numa visão de movimentos seculares de busca da tolerância religiosa e adaptação a uma sociedade de pujança comercial.

Dessa forma, a história da historiogra- 
fia é tragada para uma história cultural, de análise dos pressupostos historiográficos sob a ótica das atividades exercidas pelos historiadores nos anos que escreveram. Para se entender a historiografia, seria necessário não só analisar seus pressupostos, mas o contexto em que foi escrita, de modo a entender historicamente esses próprios pressupostos. Para terminar a absorção da história da historiografia ao contextualismo linguístico, Pocock discursará sobre a importância de se entender a intencionalidade textual3. Os historiadores

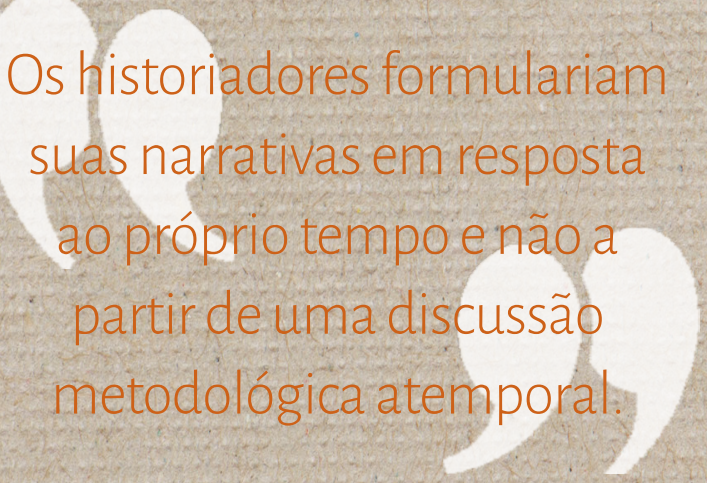

diversos. Consequentemente, veríamos um historiador em um mundo informacional preocupado em desacreditar as conclusões históricas de Edward Cibbon, indivíduo de um tempo em que até mesmo viajar de carroça era perigoso.

Ao transformar a historiografia em produto da história, Pocock dará um perigoso passo em direção ao abismo do historicismo anteriormente citado. Esse passo inevitavelmente faz balançar algumas das fundações da validade e da possibilidade do conhecimento histórico e, certamente, contradiz um amformulariam suas narrativas em resposta ao próprio tempo e não a partir de uma discussão metodológica atemporal. Assim como a história das ideias elencava seu panteão e fazia com que eles discutissem entre si num mundo político quintessencial, parte da história da historiografia faria o mesmo ao listar os inovadores historiadores que se digladiam com métodos atemporais

3 A discussão sobre intencionalidade autoral é longa demais para alguns parágrafos em um artigo. No entanto, cabe ao articulista ponderar que para Pocock, assim como para Skinner, a procura da intencionalidade não é a busca pelos motivos mentais que fizeram um autor escrever um texto, e sim a interpretação da efetivação do texto em uma sociedade, de entendê-lo como ação que intenta modificar a própria realidade. Para mais, ler.o artigo Motives, Intentions and Interpretation, de Quentin Skinner (2002). bicioso Pocock que, no começo de sua carreira, pretendia definir as funções de cada disciplina.

Em uma historicista queda livre, Pocock produzirá alguns trabalhos tão ousados quanto curiosos. Nos referimos ao seu The Discovery of Islands (2005), que introduzirá o próprio autor nas análises da história da Nova Zelândia. A intenção seria a de explicitar sua condição histórica de pertencimento a um tempo, espaço e linguagem, para destacar sua própria análise histórica como histórica, parcial (POCOCK, 2005, p. 3-4). Numa espécie de historiografia autobiográfica 
do outro, o livro tem a proposta de ler a história a partir das condições históricas dos historiadores, não se preocupando com documentos primários, mas sim com as narrativas sobre a Nova Zelândia, identificando o que essas narrativas dizem da época de sua escritura e não o que analisam. As narrativas historiográficas se tornam, desse modo, documentos de uma nova escrita da história. oda comunidade política, por exemplo, selocalizaria no mundo a partir de histórias do seu passado, definindo seus costumes e tradições, ao mesmo tempo que toda história seria a forma de identificar a si mesmo numa narrativa maior, que excede a existência do indivíduo. A história seria o elo de ligação do eu (self) a uma comunidade política. mas, em alguns outros textos da mesma época, ele parece encontrar um caminho do meio, o da historiografia como linguagem política. Em seu The Historian as Political Actor (1996), editado no livro Political Thought and History, de 2009, um binômio teórico, história e comunidade política, é trabaIhado para embasar a sua historiografia, sendo o segundo termo referente a um lugar de distribuição de poder, e o primeiMas algum conhecimento histórico se sustentaria nesse turbilhão historicista, de modo a acusar o próprio perspectivismo do self na história como algo histórico, bem como dizer que é histórico historicizar a história?

\section{Pocock e a historiografia como linguagem política}

Poderíamos acusar Pocock de ter sido desacreditado pela própria proposta ro à narrativa de eventos e situações que teriam ocorrido no passado (POCOCK, 2009, p. 218). A generalidade de tais definições serve justamente para a adaptação das categorias em cada situação especéfica: No caso da definição de história, por exemplo, abarcaria povos com temporalidades diferentes, como os maoris, que falam da história não como algo atrás deles, mas à sua frente, por uma questão de autoridade e peso do passado sobre o presente. E, no caso das comunidades políticas, abrangeria sociedades, setores e instituições que, para além do Estado, retivessem parte 
do poder distribuído. Ao definir os binômios, Pocock também define a relação entre eles.

Toda comunidade política, por exemplo, se localizaria no mundo a partir de histórias do seu passado, definindo seus costumes e tradições, ao mesmo tempo que toda história seria a forma de identificar a si mesmo numa narrativa maior, que excede a existência do indivíduo. A história seria o elo de ligação do eu (self) a uma comunidade política. Por esse mesmo motivo, Pocock defende que toda a história, mesmo as identitárias, deveriam fazer esse caminho, oferencendo a membros dessa comunidade política diferentes narrativas de identificação, integrando melhor seus cidadãos.

\section{A história seria esse} elo de ligação das experiências através das narrativas. Assim, ela se tornaria linguagem, formatando as mentes e experiências de pessoas e comunidades, ao mesmo tempo em que possibilitaria o diálogo de perspectivas diferentes, num jogo de langues e paroles. A historiografia como linguagem não faria das várias narrativas históricas concorrentes entre si, como linguagens políticas que se digladiam por legitimidade? Assim sendo, a história não se tornaria de vez retórica? Pocock (2009, p. 223) acena que sim, dizendo que o historiador descende dos sofistas, dos retóricos, e não dos filósofos.

As historiografias, como linguagens políticas, concorreriam por legitimidade em uma comunidade política com seus órgãos de alocação de poder e de cidadãos se reconhecendo em algumas das narrativas. Ao entender a história como ligada a essa comunidade, entende-se ela como receptáculo de maior e menor poder, de acordo com o seu grau de convencimento (retórica) e o seu grau de favorecimento de instituições, dotadas de poder.

Como retórica, a historiografia procuraria o convencimento de setores da sociedade para se estabelecer 
como narrativa convincente, ou oficial. A imersão dessas narrativas em instituições como o Estado, a universidade ou até mesmo órgãos de direitos hùmanos, dependeria do convencimento de grupos específicos ligados a essas instituições. Ao mesmo tempo, ao ser reconhecida, essa narrativa transformar-se-ia, também, em discurso de autoridade das próprias instituições. Não por acaso instituições procuram seus historiadores oficiais, narradores não só dos costumes da instituição, mas também de sua força, da potência de sua tradição.

Essa forma de se perceber a historiografia em relação à linguagem, à narrativa e ao poder modifica também a concepção de historiador, não mais como uma simples especialização da divisão do trabalho, mas também como um ator político, de lances e p.aroles, que visa a modificação ou manutenção da alocação de poder, mesmo quando não está consciente disso. A academia de história se torna, nas palavras de Pocock, uma guilda que, apesar de abrigar linguagens e narrativas diversas, ainda sim se preocupa em regulamentar e legitimar o ofício, se transformando em um locus de poder. Atestar tudo isso não é, no entanto, se colocar fora das relações de poder. Vociferar a mudança muito menos. Todo discurso, a favor ou contra essa relação, somente realocaria, ou reforçaria, as relações de poder e de convencimento da historiografia.

Se a história cria essa dinâmica interna em uma comunidade política, ela cria, também, outra de reconhecimento e ação da própria comunidade. Ao narrar tradições e decifrar experiências, a história seria uma ferramenta de soberania da comunidade política, ao possibilitar a ela mesma se inserir nos acontecimentos do mundo e traçar os planos para o futuro. Narrar-se seria tomar consciência de experiências passadas em vista de ações para a construção de um futuro que lhe seja desejável. Seria uma experiência de busca de autonomia e de execução da soberania (POCOCK, 2009, p. 257-271).

Essa concepção de comunidade política nos parece ser um vulto das comunidades científicas de Thomas Kuhn e é sustentada, ao nosso ver, pelo paradigma temporal do futuro como uma abertura secular de modulação do presente. À medida que esse paradigma não responda mais aos estímulos e pro- 
blemas de nosso tempo, o que ocorrerá com a disciplina histórica? Entrará em um processo de declínio e queda ou será redefinida por uma outrá comunidade detentora de novas linguagens e novos poderes?

Tomando um papel oculto de profeta, Pocock nos alerta, desde a década de 1990, para o fim desse paradigma. Aeconomia global, pós-industrial, teria enfraquecido o sentimento de pertencimento das novas gerações às suas respectivas culturas e comunidades políticas. Uma classe executiva estaria impondo o fim das fronteiras para a livre circulação de commoditties e informações (POCOCK, 2005, p. 303), o que abalaria a relação história-comunidade política. O enfraquecimento do sentimento de pertencimento a uma cultura ou comunidade política enfraqueceria a necessidade de se narrar uma história. Os indivíduos não se veriam mais capazes de formular um futuro ou de pertencer a ele por não estarem mais identificados a essas comunidades. Essa conclusão de Pocock deriva, porém, de dois pressupostos de seu próprio tempo, o de Estado-Nação e o de comunidade política como locus de dissenso, ao estilo maquiaveliano. 0 dissenso seria explicitado em narrativas que, digladiando com as outras, pretenderiam se tornar oficiais e, assim, moldar as decisões daquela comunidade, política. Para que isso ocorra, é necessário que as narrativas, apesar de concorrentes, compartilhem os pontos a serem debatidos. Narrativas que se fecham em si mesmas, sem combaterem pela significação desses pontos em comum, estariam fadadas a não participarem da comunidade política (POCOCK, 2009; p. 266). A associação entre Estado e Nação seria responsável, portanto, por indicar esses pontos a serem debatidos e conquistados. No entanto, o movimento pós-nacional das últimas décadas comprometeria essa associação ao atacar esse locus do dissenso narrativo em favor de histórias de enfoque estritamente identitário.

Um segundo lluminismo, pós-moderno, responderia por esse chamado do mundo aberto e, com sua preocupação da narrativa da identidade, arruinaria o binômio história e comunidade política, numa época em que as pessoas prefeririam ter identidades desassociadas da história da comunidade e que falariam de um eu estendido sem falar de um nós pluralizado. 
O paradigma do futuro secular em aberto parece estremecer e Pocock, comoum vetor de antítese da coruja de Minerva, procura frear essa tendência reafirmando o papel das narrativas para as comunidades políticas.

\section{Referências}

AMBROSINI, Diego Rafael. As 'viradas' linguística, histórica e interpretativa: novos paradigmas teóricos em História das Ideias e a relação estrutura/agência. In: OSTRENSKY, Eunice; TIERNO, Patricio (Orgs.). Teoria, Discurso e Ação Política. São Paulo: Alameda, 2013. p. 259-276.

APPLEBY, Joyce. Liberalism and Republicanism in the Historical Imagination. Massachusetts: Harvard University, 7992.

BOUCHER, David. Texts in Context: Revisionist Methods for Studying the History of Ideas. Dordrecht: Martinus Nijhoff, 1985a.

Language, Politics \& Paradigms: Pocock \& the Study of Political Thought. Polity, Cambridge, v. 17, n. 4. p. $767-776,1985$ b.

GEERKEN, John H. Pocock and Machiavelli: Structuralist Explanation in History. Journal of the History of Philosophy, Baltimore, v. 27, p. 309-378, 1979.

JASMIN, Marcelo Gantus. História dos Conceitos e Teoria Política e Social: referências preliminares. Revista Brasileira de Ciências Sociais, São Paulo, v. 20, n. 57, p. 27-38, fev. 2005.

JASMIN, Marcelo Gantus; FERES JÚNIOR, João (Orgs.). História dos Conceitos: Debates e perspectivas. Rio de Janeiro: PUC-R]; Loyola; IUPER], 2006.

OSTRENSKY, Eunice; TIERNO, Patricio (Orgs.). Teoria, Discurso e Ação Política. São Paulo: Alameda, 2013.

PELTONEN, Markku. Classical Humanism and Republicanism in English Political Thought: $1570-$ 1640. Cambridge: Cambridge University, 2004.

PHILLIPSON, Nicholas; SKINNER, Quentin (Orgs.). Political Discourse in Early Modern Britain. Cambridge: Cambridge University, 1993.

POCOCK, John C. A. A Branch of the Subject. Cambridge Review, Cambridge, p. 423-425, mar. 1958.

The History of Political Thought: A Methodological Inquiry. In: LASLETT, Peter; RUNCIMAN, W. G. (Orgs.). Philosophy, Politics and Society. Oxford: Basil Blackwell, 1964. p. 183-202.

Politics, Language and Time: essays on political thought and history. New York: Atheneum, 1971. 
The Machiavellian Moment Revisited: A Study in History and Ideology. The Journal of Modern History, Chicago, v. 53, n. 1, p. 49-71, mar. 1981.

Virtue, Commerce and History: Essays on Political Thought and History, Chiefly in the Eighteenth Century. Cambridge: Cambridge,University, 1985.

The Ancient Constitution and the Feudal Law: A Study of English historical Thought in the Seventeenth Century. Cambridge: Cambridge University, 1987.

The historian as political actor in polity, society and academy. Journal of Pacific Studies, University of South Pacific, v. 20, p. 89-172, 1996.

The Machiavellian Moment: Florentine Political Thought and the Atlantic Republican Tradition (with a new afterword by the author). Princeton: Princeton University, 2003.

Barbarism and Religion: The Enlightments of Edward Gibbon, 1737-1764. Cambridge: Cambridge University, 2004, v. 1 .

The Discovery of Islands: Essays on British history. Cambridge: Cambridge University, 2005.

Political Thought and history: Essays on Theory and Methodology. Cambridge: Cambridge University, 2009.

Linguagens do ldeário Político. São Paulo: Edusp, 2013a.

dina, $2013 b$.

Cidadania, Historiografia e Res Publica: Contextos do Pensamento Político. Coimbra: Alme-

SKINNER, Quentin. Visions of Politics: Regarding Methods. Cambridge: Cambridge University, 2002.

VENTURI, Franco. Utopia e Reforma no lluminismo. Bauru: Edusc, 2003. 